\title{
PEMBERDAYAAN MASYARAKAT RETARDASI MENTAL SEBAGAI UPAYA MENINGKATKAN KESEHATAN JIWA MELALUI METODE PROVERASI
}

\author{
Dahlia Novarianing Asri ${ }^{1)}$, Dian Ratnaningtyas Afifah ${ }^{2)}$ \\ ${ }^{1}$ Fakultas Keguruan dan Ilmu Pendidikan, Universitas PGRI Madiun, Madiun \\ novarianing@gmail.com \\ ${ }^{2}$ Fakultas Keguruan dan Ilmu Pendidikan, Universitas PGRI Madiun, Madiun \\ dee4n58@gmail.com
}

\begin{abstract}
ABSTRAK
Desa Krebet merupakan salah satu dari empat desa di Kecamatan Jambon Kabupaten Ponorogo yang mayoritas penduduknya mengalami gangguan retardasi mental, sehingga julukan "Kampung Idiot" masih melekat hingga saat ini di masyarakat tersebut. Kondisi geografis daerah yang terpencil, tanah tandus dan gersang serta dataran yang dikelilingi pegunungan kapur menyebabkan minimnya pelayanan pendidikan, kesehatan yang layak, dan sebagian besar masyarakat berada di bawah garis kemiskinan. Dalam menjalani kehidupan sehari-hari warga masyarakat yang mayoritas mengalami retardasi mental akan berdampak terhadap kesehatan jiwa masyarakat "kampung idiot", sehingga diperlukan suatu penanganan yang serius dengan memberdayakan masyarakat desa setempat dalam upaya meningkatkan kesehatan jiwa melalui metode proverasi (promosi, prevensi, kurasi, rehabilitasi). Metode proverasi dilakukan melalui serangkaian kegiatan yang meliputi penyuluhan dan bimbingan sosial dalam menciptakan kehidupan yang sehat, baik fisik maupun psikologis, memberikan life skills kepada warga retardasi mental maupun warga masyarakat normal untuk meningkatkan pendapatan ekonomi keluarga, dan keterampilan hidup untuk memelihara diri dan mandiri dalam kehidupan seharihari.Berdasarkan hasil pelaksanaan kegiatan pengabdian kepada masyarakat yang telah dilakukan dapat disimpulkan bahwa upaya meningkatkan kesehatan jiwa dapat dilakukan melalui Metode Proverasi (Promosi, Prevensi, Kurasi, Rehabilitasi) dengan memberdayakan warga masyarakat Desa Krebet Kecamatan Jambon Kabupaten Ponorogo.
\end{abstract}

Kata kunci: Kesehatan Jiwa, Metode Proverasi, Masyarakat Retardasi Mental

\begin{abstract}
The village of Krebet is one of four villages in Jambon Sub-district, Ponorogo District where the majority of the population suffers from mental retardation, so the nickname "Kampung Idiot" is still attached to the present in the community. The geographic conditions of remote, barren and arid land and the plains surrounded by limestone ridges have resulted in inadequate education, decent health care, and the vast majority of people are below the poverty line. In daily life, the majority of people experiencing mental retardation will have an impact on the mental health of the "idiot village" community, so a serious handling by empowering local villagers to improve their mental health through proveration method (promotion, prevention, curation, rehabilitation). The proveration method is done through a series of activities which include counseling and social guidance in creating a healthy life, both physical and psychological, providing life skills to the residents of mental retardation as well as normal citizens to increase the family's economic income, and life skills to maintain themselves and be independent in life
\end{abstract}


Daily.Based on the results of the implementation of community service activities that have been done can be concluded that the effort to improve mental health can be done through Progress Method (Promotion, Prevention, Curation, Rehabilitation) by empowering the people of Krebet Village, Jambon Subdistrict, Ponorogo Regency.

Keywords: Mental Health, Progress Method, Mental Retardation Society

\section{PENDAHULUAN}

Desa Krebet Kecamatan Jambon

Kabupaten Ponorogo Jawa Timur merupakan salah satu desa yang sebagian besar warganya menyandang retardasi mental. Retardasi mental merupakan suatu keadaan disabilitas atau ketidakmampuan yang ditandai dengan fungsi intelektual di bawah rata-rata dan secara bersamaan disertai dengan rendahnya kemampuan untuk menyesuaikan diri (Maramis, 2005). Penyandang retardasi mental memerlukan perhatian khusus dari keluarga karena ketidakmampuannya dalam mengurus dan merawat diri dalam kehidupan sehari-harinya, serta keterampilan-keterampilan adaptif lainnya.

Desa Krebet Kecamatan Jambon Kabupaten Ponorogo mendapatkan perhatian secara nasional karena mayoritas penduduknya mengalami keterbelakangan mental atau disebut Orang Dengan Kecacatan (ODK), sehingga julukan "Kampung Idiot" masih melekat hingga saat ini di masyarakat. Terdapat empat desa yang sering mendapat label "Kampung Idiot" yaitu Desa Krebet dan Desa Sidoharjo di Kecamatan Jambon, serta Desa Karang Patihan dan Desa Pandak di Kecamatan Balong. Sebagian besar warga di desa-desa tersebut hidup di bawah garis kemiskinan.

Banyak faktor yang menjadi penyebab terjadinya retardasi mental pada warga kampung idiot. Faktor genetik kerap menjadi faktor utama karena kesalahan warga masyarakat yang melakukan perkawinan sedarah. Kurangnya gizi sejak terjadinya kehamilan hingga dalam kehidupan sehari-hari juga turut menjadi penyebab terjadinya keterbelakangan mental. Hal ini tidak terlepas dari minimnya tingkat pendidikan masyarakat, dan tingkat sosial ekonomi yang rendah. Warga masyarakat pernah mengalami masa dimana telah berpuluh-puluh tahun hanya mengkonsumsi makanan nasi gaplek atau nasi tiwul yang jauh dari nilai gizi. Kondisi geografis daerah yang terpencil, tanah tandus dan gersang serta dataran yang dikelilingi pegunungan kapur menyebabkan minimnya pelayanan pendidikan dan kesehatan yang layak. Faktor lain yang menjadi penyebab terjadinya keterbelakangan mental dan kecacatan pada warga masyarakat 
retardasi mental diungkapkan dari hasil penelitian Kadis Kesehatan Ponorogo (dalam Hanif \& Asri, 2013) yang menemukan adanya kandungan logam berat dan berbahaya di otak. Logam berat itu adalah $\mathrm{Pb}$ (timah hitam) dan $\mathrm{Hg}$ (mercury) kurang dari 0,1 wt persen. Logam berat tersebut termasuk dalam anorganik yang bisa menyebabkan kerusakan tiroid atau kelenjar gondok. Logam berat bisa mengikat yodium dalam air tanah sehingga pada air yang diminum di kawasan tersebut kadar yodiumnya akan sangat rendah. Logam berat berdampak pada semua makhluk hidup di kawasan tersebut.

Kondisi warga masyarakat retardasi mental ini telah banyak mendapatkan bantuan dan penanganan dari berbagai pihak, baik dari pemerintah maupun individu dan organisasi swasta yang berupa bantuan material dan imaterial. Pada kegiatan ini, salah satu upaya untuk meningkatkan kesehatan jiwa masyarakat retardasi mental dan masyarakat normal dalam mencapai kesejahteraan psikologis adalah melalui metode proverasi, yaitu metode promosi, prevensi, kurasi, dan rehabilitasi. Metode proverasi dilakukan melalui serangkaian kegiatan yang meliputi penyuluhan dan bimbingan sosial dalam menciptakan kehidupan yang sehat, baik fisik maupun psikologis, memberikan life skills kepada warga retardasi mental maupun warga masyarakat normal untuk meningkatkan pendapatan ekonomi keluarga, dan keterampilan hidup untuk memelihara diri dan mandiri dalam kehidupan sehari-hari.

Dalam pelaksanaan metode preverasi ini diperlukan peran serta pemerintah, swasta, dan masyarakat serta para pemangku kepentingan dalam bekerja sama menyelesaikan masalah dalam meningkatkan kesehatan jiwa warga masyarakat normal dan warga retardasi mental. Penanganan ini tentu saja membutuhkan kepekaan, kejelian, ketekunan, pengetahuan serta motivasi dari berbagai pihak, khususnya para kader dan pengurus Rumah Kasih Sayang (RKS) dan perangkat desa melalui karang taruna.

Target yang ingin dicapai dari kegiatan pengabdian ini adalah: (1) menciptakan metode proverasi (promosi, prevensi, kurasi, rehabilitasi) berbasis ipteks bagi warga masyarakat normal dan warga retardasi mental, dan meningkatkan kesehatan jiwa warga masyarakat normal dan warga retardasi mental. Sedangkan luaran yang ingin dihasilkan dari kegiatan pengabdian ini adalah: (1) meningkatnya kesehatan jiwa dari pelaksanaan metode proverasi (promosi, prevensi, kurasi, dan rehabilitasi) yang telah dirintis dan dikembangkan oleh pengurus dan kader Rumah Kasih Sayang dan 
Pemerintah Desa Krebet, dan (2) Pengurus dan kader Rumah Kasih Sayang (RKS) dan Pemerintah Desa Krebet siap melakukan dan melanjutkan metode proverasi di masyarakat "kampung idiot".

\section{METODE PELAKSANAAN}

Solusi yang ditawarkan untuk mengatasi permasalahan yang telah diuraikan di atas, dilakukan metode pelaksanaan sebagai berikut: (1) Melakukan observasi dan menggali informasi kepada mitra tentang kondisi dan jumlah warga masyarakat "kampung idiot", (2) Melakukan koordinasi dengan Pengurus RKS terkait pelaksanaan kegiatan yang menerapkan metode proverasi (promosi, prevensi, kurasi, rehabilitasi), (3) Pelaksanaan Metode Proverasi melalui serangkaian kegiatan yang meliputi penyuluhan dan bimbingan sosial dalam menciptakan kehidupan yang sehat, baik fisik maupun psikologis, memberikan life skills kepada warga retardasi mental maupun warga masyarakat normal untuk meningkatkan pendapatan ekonomi keluarga, dan keterampilan hidup untuk memelihara diri dan mandiri dalam kehidupan sehari-hari.

Dalam menyelesaikan persoalan yang dialami oleh mitra, maka diperlukan tenaga-tenaga ahli untuk terlibat dalam rangkaian kegiatan yaitu psikolog, tenaga kesehatan dari dinas kesehatan setempat, dan sosiolog. Psikolog dilibatkan dalam rangkaian kegiatan promosi, prevensi, kurasi, dan rehabilitasi yang lebih menekankan pada aspek psikologis dalam meningkatkan kesehatan jiwa warga masyarakat "kampung idiot" dalam menjalani kehidupan sehari-hari. Tenaga kesehatan dilibatkan dalam kegiatan pengarahan dan penyuluhan akan hidup sehat, dan memberikan pengetahuan tentang pentingnya garam beryodium dalam kesehatan tubuh. Selain itu, tenaga kesehatan juga memberikan keterampilan untuk pemeliharaan diri, baik kepada warga masyarakat normal maupun warga retardasi mental. Sedangkan sosiolog dilibatkan dalam kegiatan sosial yang melibatkan warga masyarakat dengan memberikan keterampilan sosial dalam berinteraksi antara warga masyarakat normal dengan warga retardasi mental.

\section{HASIL DAN PEMBAHASAN}

Berdasarkan rangkaian kegiatan yang telah dilaksanakan di Rumah Kasih Sayang, segenap pengurus Rumah Kasih Sayang, kader, warga masyarakat, dan Orang Dengan Kecacatan (ODK) menyambut baik kegiatan tersebut. Meskipun beberapa kegiatan pengabdian kepada masyarakat bukan merupakan kegiatan baru bagi mereka, namun warga masyarakat dan Orang Dengan Kecacatan (ODK) sangat antusias dalam menjalani kegiatan- 
kegiatan tersebut, karena pengurus Rumah Kasih Sayang telah mengadakan kegiatan rutin setiap hari Minggu untuk melakukan pendampingan bagi warga masyarakat dan ODK.

Pada kegiatan penyuluhan tentang hidup bersih sehat dan higienis, dihadirkan personil dari Dinas Kesehatan Kabupaten Ponorogo yaitu Bapak Yuli Pratikno, S.KM., M.Kes. Materi penyuluhan memfokuskan pada penanggulangan Gangguan Akibat Kurang Iodium (GAKI). Sebagian besar Orang Dengan Kecacatan (ODK) di Desa Krebet Kecamatan Jambon Kabupaten Ponorogo disebabkan karena GAKI. Pemateri menekankan bahwa setiap rumah tangga, khususnya ibu rumah tangga wajib menggunakan garam beryodium dalam mengolah makanan. Beberapa waktu yang lalu, pemerintah provinsi memberikan bantuan berupa garam beryodium sebagai bentuk bantuan dalam menanggulangi GAKI, namun saat ini bantuan tersebut sudah berhenti dan dialihkan dalam bentuk lain. Kegiatan sosialisasi ini juga dihadirkan salah satu ODK yang bernama Satu, yang menyandang gangguan bisu tuli total sejak lahir, dan gangguan ini disebabkan karena kurangnya yodium.

Pada kegiatan promosi kesehatan mental dengan materi tentang hidup sehat secara psikologis disampaikan oleh tim peneliti yang memiliki latar belakang bidang ilmu psikologi. Materi sosialisasi difokuskan pada aspek psikologi yang meliputi gangguan retardasi mental, gangguan kecemasan, penyesuaian diri dan penyesuaian sosial. Materi ini diberikan dengan tujuan agar para kader dan warga masyarakat yang sehat dapat memahami gejala-gejala psikologis yang muncul pada warga retardasi mental. Selama ini, penanganan pertama yang dilakukan oleh warga masyarakat jika menemukan warga retardasi mental mengalami serangan panic, maka oleh warga sekitar langsung dilarikan ke puskesmas kesehatan jiwa yang ada di Kecamatan Jambon.

Kegiatan prevensi kesehatan dilakukan oleh peneliti dengan memberikan pengetahuan, sikap dan keterampilan kepada keluarga dalam merawat dan memelihara diri anggota keluarga yang menyandang retardasi mental yang meliputi cara menggosok gigi yang benar, makan sendiri, mandi, memakai pakaian sendiri, dan melatih membersihkan rumah. Pemberian pengetahuan dan keterampilan ini dinilai penting karena mencegah agar kondisi warga yang mengalami retardasi mental tidak bertambah parah namun justru diharapkan lebih baik dengan memberikan keterampilanketerampilan pemeliharaan diri, seperti mengajarkan gosok gigi yang benar, cara makan sendiri, memakai pakaian sendiri dan melatih 
membersihkan rumah. Kegiatan prevensi ini dilanjutkan pada pertemuan berikutnya dengan melakukan kunjungan ke rumah warga retardasi mental untuk memantau kegiatan pemeliharaan diri dan kebersihan rumah serta tempat tinggal sekitar.

Setelah melakukan kunjungan ke rumah warga retardasi mental dan Orang Dengan Kecacatan (ODK), dilakukan penyerahan bantuan berupa makanan dan peralatan kebersihan diri. Tujuan diberikan bantuan ini adalah untuk meningkatkan kesehatan dan kesejahteraan diri warga retardasi mental dan Orang Dengan Kecacatan (ODK). Keluarga dan warga retardasi mental serta Orang Dengan Kecacatan (ODK) sangat antusias dalam menerima bantuan, mengingat keadaan sosial ekonomi warga masyarakat masih dibawah garis kemiskinan.

Pelaksanaan kegiatan dengan metode kurasi dilakukan oleh tim peneliti dengan didampingi pengurus dan kader Rumah Kasih Sayang dengan memberikan pelatihan keterampilan hidup kepada warga masyarakat dan warga retardasi mental yang terlatih. Pemberian pelatihan keterampilan hidup untuk meningkatkan pendapatan ekonomi keluarga dilakukan dengan cara memberikan pelatihan dan pendampingan dalam membuat produksi kerajinan tangan berupa tas anyaman, keset dari kain perca dan kemoceng. Selama ini, kader Rumah Kasih Sayang telah memberikan pelatihan pembuatan bros dari kulit jagung kepada warga masyarakat dan ODK karena di Desa Krebet memiliki sumber daya alam berupa tanaman jagung. Ketika panen jagung, warga menjual jagung ke pasar atau pengepul, sedangkan kulitnya dimanfaatkan untuk diolah menjadi barang asesoris.

Di bidang pengolahan pangan, tim peneliti memberikan pelatihan dan pendampingan dalam membuat abon lele yang merupakan hasil pengolahan dari ikan lele. Mengingat di daerah tersebut beberapa masyarakat memiliki usaha budidaya lele, maka hasil panen ikan lele selain dijual juga dapat diolah menjadi abon lele yang memiliki nilai ekonomis. Sedangkan di bidang peternakan, warga masyarakat dibekali budidaya semut rangrang.Pemilihan pelatihan budidaya semut rang-rang dikarenakan pada daerah tersebut banyak sekali ditemukan semut rang-rang di sekitar tempat tinggal.

Setelah diberikan beberapa pelatihan keterampilan hidup kepada pengurus dan kader Rumah Kasih Sayang dan warga masyarakat baik warga masyarakat yang normal maupun Orang Dengan Kecacatan (ODK) maka selanjutnya diberikan pelatihan manajemen usaha yang bertujuan untuk membekali para 
pengurus dan kader Rumah Kasih Sayang (RKS) serta warga masyarakat agar dapat mengelola usaha dengan baik sehingga dapat menjalankan usahanya dengan baik dan memberikan keuntungan.

Kegiatan dengan metode rehabilitasi mental dilakukan oleh tenaga psikolog yang dirangkap oleh anggota peneliti. Sebelum diberikan layanan bimbingan sosial, terlebih dahulu pengurus dan kader Rumah Kasih Sayang (RKS) dan warga masyarakat normal diberikan penyuluhan tentang materi rehabilitasi mental yang difokuskan pada bagaimana penanganan, penyembuhan dan mengembalikan individu yang mengalami retardasi mental untuk hidup normal dan bersosialisasi dengan warga masyarakat lainnya. Hal yang sudah dilakukan oleh warga masyarakat terhadap individu retardasi mental dan Orang Dengan Kecacatan (ODK) adalah tetap melibatkan mereka dalam kegiatan-kegiatan kemasyarakatan dan kegiatan dalam mengasah keterampilan dalam memproduksi barang yang bersifat ekonomis. Meskipun individu mengalami retardasi mental dan kecacatan, namun di antara mereka justru memiliki kelebihan yaitu sangat terampil dalam membut produksi tangan, misalnya dalam pembuatan keset, kemoceng, dan tas anyaman. Selanjutnya, tim peneliti dengan dibantu oleh ketua pengurus Rumah Kasih Sayang (RKS) memberikan layanan bimbingan sosial dengan teknik dinamika kelompok kepada warga retardasi mental untuk melatih interaksi sosial dengan warga lainnya.

\section{SIMPULAN DAN SARAN}

Berdasarkan hasil pelaksanaan kegiatan pengabdian kepada masyarakat yang telah diuraikan di atas, dapat disimpulkan bahwa upaya meningkatkan kesehatan jiwa dapat dilakukan melalui Metode Proverasi (Promosi, Prevensi, Kurasi, Rehabilitasi) dengan memberdayakan warga masyarakat Desa Krebet Kecamatan Jambon Kabupaten Ponorogo.

Berdasarkan simpulan di atas, beberapa saran ditujukan kepada tokoh masyarakat, donatur, dan pemerintah, baik pemerintah desa, daerah, maupun pusat sebagai berikut: (1) bantuan yang diberikan kepada warga masyarakat, tidak hanya sekedar berbentuk materi, seperti sembako namun juga berupa bantuan imateri berupa pemberian pelatihan-pelatihan psikologis yang dapat membantu warga masyarakat, individu retardasi mental dan Orang Dengan kecacatan (ODK) dalam mengembangkan aspek psikologis dari masing-masing individu sehingga akan berpengaruh dalam menjalani kehidupan sehari-hari, (2) perlu adanya kerjasama antara pemerintah desa, daerah, maupun pusat dalam memperhatikan dan 
mengembangkan Rumah Kasih Sayang binaan Kementerian Sosial Republik Indonesia sehingga akan lebih bermanfaat dan lebih optimal dalam pelaksanaaan di setiap kegiatannya, dan (3) perlu diciptakan berbagai macam kegiatan di Rumah Kasih Sayang sehingga menuntut pihak-pihak tertentu seperti donatur, peneliti, LSM untuk lebih meningkatkan kreatifitas dalam menciptakan kegiatan di Rumah Kasih Sayang sehingga warga masyarakat, individu retardasi mental dan Orang Dengan Kecacatan (ODK) semakin berminat dan menekuni setiap kegiatan yang dilaksanakan di Rumah Kasih Sayang.

\section{DAFTAR PUSTAKA}

Hanif, M. \& Asri, D.N. (2013). Perilaku dan Interaksi Sosial Warga Kampung Idiot di Desa Sidoharjo dan Krebet Kecamatan Jambon Kabupaten Ponorogo (Studi Fenomenologi Masyarakat Retardasi Mental). Laporan Penelitian. Penelitian Fundamental DIKTI.

Maramis, W.F. (2005). Ilmu Kedokteran Jiwa. Surabaya: Airlangga University Press.

www.bks3jatim.or// diakses tanggal 12 April 2015. 